\title{
Fatigue Properties of Ultra-Fine Grain Austenitic Stainless Steel and the Effect of Hydrogen
}

\author{
Masanobu Kubota ${ }^{1, *}$, Arnaud Macadre ${ }^{1}$, Koichi Mori $^{2}$ and Ryo Mori $^{2}$ \\ ${ }^{1}$ International Institute for Carbon-Neutral Energy Research (WPI-I2CNER), Kyushu University, 744 Motooka, Nishi-ku, Fukuoka, \\ Japan \\ ${ }^{2}$ Graduate School of Mechanical Engineering, Kyushu University, 744 Motooka, Nishiku, Fukuoka, Japan
}

\begin{abstract}
The fatigue properties of ultra-fine grain austenitic steel (UFG16-10), which has a $1 \mu \mathrm{m}$ average grain size, were studied as part of the project aimed at the development of high-strength low-cost stainless steels for hydrogen service. The fatigue properties of the UFG16-10 were compared with that of a coarse grain material with the same chemical composition (CG16-10) and two kinds of commercial steels, JIS SUS316 and JIS SUH660. The fatigue strength of the UFG16-10 was 2.8 times higher than that of the CG16-10. The effect of hydrogen on the fatigue limit of the UFG16-10 was not significant. However, the fatigue life of the UFG16-10 was reduced by hydrogen in the short life regime. In the fatigue crack growth test, the UFG16-10 showed a good crack growth resistance that was equivalent to that of the SUH660 and significantly higher than that of the SUS316. However, the crack growth rate was significantly accelerated by hydrogen. The cause of the hydrogen-assisted fatigue crack growth of the UFG16-10 was transformation of the microstructure at the crack tip from austenite to strain-induced martensite. This was also the cause of the reduced fatigue life of the hydrogen-charged UFG16-10.
\end{abstract}

\section{Introduction}

The studies of ultra-fine grained materials produced by ECAP [1], HPT [2], ARB [3], Warm tempforming [4], HCR [5], etc., are actively being advanced. An austenitic stainless steel, which has a grain size less than $2 \mu \mathrm{m}$, has been commercialized since 2013 [6]. Regarding the research on the fatigue properties of the ultra-fine grain materials, a unique fatigue mechanism was found such that the recrystallization at the crack tip during crack propagation occurs in low-melting-point materials such as copper [1,8] and a magnesium alloy [7]. This resulted in no improvement in the fatigue strength due to the grain growth, whereas the static strength was significantly improved by the grain refinement. On the other hand, a significant increase in the fatigue strength is obtained in carbon steels [9-11] and stainless steels [5, 12] by the grain refinement. Grain refinement using a friction machining tool was applied to the specimen surface, then improved fatigue strength was obtained [13]

However, the mechanism that causes an increase in the fatigue strength in the ultra-fine grain steels remains unclear, for instance, the fatigue strength increases with the degree of grain refinement treatment, but it then decreases with further treatment [9]. In addition, a negative effect on the improvement of the fatigue strength that the crack growth resistance of a low carbon steel is reduced by the grain refinement was also reported [15]. Specifically, the contribution of the fact that "grains are small" to the improved fatigue strength is not sufficiently understood, since there are many other factors which can influence the fatigue behavior such as an increase in the initial dislocation density, phase transformation during grain refinement process, formation of micro-defects, change in distribution of inclusions, etc. Further studies are needed in order to elucidate the fatigue mechanism in the ultra-fine grain materials.

According to the recent studies on hydrogen-assisted fracture related to fuel cell vehicles and hydrogen refuelling stations, $316 \mathrm{~L}$ austenitic stainless steel was not susceptible to hydrogen during slow strain rate testing and fatigue crack growth test in high-pressure hydrogen [16]. However, the yield strength was relatively low. On the other hand, Cr-Mo steels had a higher yield strength, but hydrogen significantly reduced the ductility [17] and accelerated the crack growth [18]. Therefore, development of a new alloy that have both high-strength and hydrogen compatibility is required.

In this context that grain refinement is a promising method to develop high-strength material and austenitic stainless steels are hydrogen compatible but low strength, the fatigue properties of an austenitic stainless steel having a $1 \mu \mathrm{m}$ average grain size and the effect of hydrogen were studied.

\section{Materials}

Corresponding author: Kubota.masanobu.304@m.kyushu-u.ac.jp 
The ultra-fine grain austenitic stainless steel used in this study was produced by a thermo-mechanical treatment which had been developed by Takaki et al. [19, 20]. Figure 1 shows the conditions of the thermo-mechanical treatment. The grain refinement was achieved by reverse transformation of the strain-induced martensite to austenite following a cold rolling with a $90 \%$ reduction rate. Therefore, the chemical composition that was optimized for this grain-refinement process was for a semi-stable austenitic stainless steel that can easily transform to strain-induced martensite during the cold rolling [19]. Table 1 shows the chemical composition of the material. The ultra-fine grain austenitic stainless steel used in this study is mainly consisted of 16 mass $\% \mathrm{Cr}$, 10 mass $\% \mathrm{Ni}$ and $\mathrm{Fe}$ (balance). Therefore, the material was labelled as UFG16-10 in this paper.

The grain size was controlled by the temperature during the reverse transformation from strain-induced martensite to austenite. A coarse grain $16 \mathrm{Cr}-10 \mathrm{Ni}$ steel was also produced from the same ingot as the UFG1610 , and was used as the reference material. The average grain size was $21 \mu \mathrm{m}$. This material was labeled as CG16-10. In addition, two commercial steels, JIS SUS316 and JIS SUH660, were also used to compare the fatigue properties with the UFG16-10. The SUS316 had $\mathrm{Cr}$ and $\mathrm{Ni}$ contents similar to that of the $16 \mathrm{Cr}-10 \mathrm{Ni}$ steel. The SUH660, which was an alloy similar to A286, had approximately the same ultimate tensile strength (UTS) as that of the UFG16-10. The heat treatment was solution heat treatment by heating at $1303 \mathrm{~K}$ for 10.8 ksec followed by rapid cooling for the SUS316, and precipitation hardening at $833 \mathrm{~K}$ for $3.6 \mathrm{ksec}$ followed by air cooling for the SUH660. The chemical composition of the reference materials is also shown in Table 1.

The microstructure of the materials is shown in Fig. 2. Since it was hard to observe $1 \mu \mathrm{m}$ grains by an optical microscope, the microstructure was observed by electron back scatter diffraction patterns (EBSD). The average grain size of the test materials was $1 \mu \mathrm{m}$ for the UFG16$10,21 \mu \mathrm{m}$ for the CG16-10, $76 \mu \mathrm{m}$ for the SUS316, and $10 \mu \mathrm{m}$ for the SUH660.

The mechanical properties of the materials are shown in Table 2. The yield strength and the ultimate tensile strength of the $16 \mathrm{Cr}-10 \mathrm{Ni}$ steel are significantly improved by the grain refinement. For more details of the tensile properties of the UFG16-10, Ref. [21] is available. The UTS of the CG16-10 was comparable to that of the SUS316. The UTS of the SUH660 is the same level as that of the UFG16-10. However, the elongation and reduction of area were significantly higher in the UFG16-10 than in the SUH660. The relation between grain refinement and ductility change depends on the material, grain refinement process and post heat treatment. There are examples of

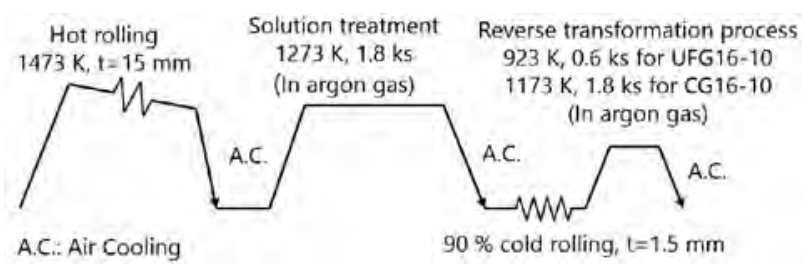

Fig. 1. Thermo-mechanical treatment for production of ultrafine grain austenitic steel developed by Takaki et al.

Table 1. Chemical composition of the materials (mass\%).

\begin{tabular}{llcccccccccccc}
\hline Material & C & Mn & Si & P & S & NI & Cr & Mo & V & Al & TI & B & N \\
\hline UFG16-10 & 0.002 & 0.08 & 0.002 & 0.003 & 0.002 & 10.1 & 16.4 & - & - & & & & 0.032 \\
CG16-10 & \\
\hline SUS316 & 0.04 & 1.30 & 0.029 & 0.0036 & 0.0027 & 10.01 & 16.80 & 2.02 & & & & & \\
\hline SUHB80 & 0.03 & 0.38 & 0.12 & 0.017 & 0.001 & 24.18 & 13.75 & 1.10 & 0.23 & 0.15 & 2.28 & 0.003 & - \\
\hline
\end{tabular}
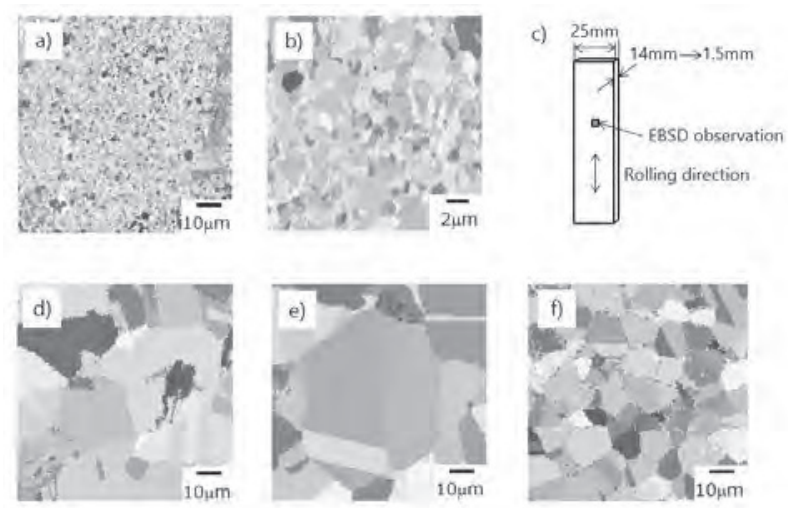

g)

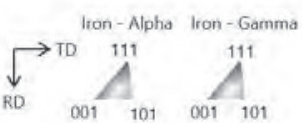

Fig. 2. Microstructure of the ultra-fine grain austenitic steel and reference materials observed by EBSD. The figures are crystal orientation map. a) UFG16-10. The average grain size was $1 \mu \mathrm{m}$. b) Magnified image of a). c) Observed area for the UFG16-10. d) CG16-10. The average grain size was $21 \mu \mathrm{m}$. e) SUS316. The average grain size was $76 \mu \mathrm{m}$. f) SUH660. The average grain size was $10 \mu \mathrm{m}$. g) Crystal orientation.

Table 2. Mechanical properties of the materials

\begin{tabular}{cccccc}
\hline Material & $\begin{array}{c}\text { Yield strength } \\
\sigma_{\gamma}, \sigma_{02}(\mathrm{MPa})\end{array}$ & $\begin{array}{c}\text { UTS } \\
\sigma_{\mathrm{B}}(\mathrm{MPa})\end{array}$ & $\begin{array}{c}\text { Elongation } \\
\delta(\%)\end{array}$ & $\begin{array}{c}\text { Reduction of } \\
\text { area } \phi(\%)\end{array}$ & HV1 \\
\hline UFG16-10 & 585 & 793 & 50.0 & 76.1 & 295 \\
\hline CG16-10 & 156 & 629 & 66.2 & 84.0 & 145 \\
\hline SUS316 & 242 & 610 & 81.8 & 81.3 & 163 \\
\hline SUH660 & 495 & 827 & 35.0 & 46.0 & 260 \\
\hline
\end{tabular}

both the reduction in ductility $[1-3,5,8,12]$ and increase in ductility $[4,7,9,10]$. In this study, the grain refinement was effective in improving the tensile strength without a drastic degradation of the ductility.

The effect of hydrogen was characterized by hydrogen-charged specimens. The specimens were exposed to $10 \mathrm{MPa}$ hydrogen gas at $543 \mathrm{~K}$ for $72 \mathrm{~h}$. The hydrogen concentrations of the materials measured by a thermal desorption spectrometry (TDS) are shown in Fig. 
3. For the measurement, several hydrogen-charged samples with different thicknesses were prepared. As shown in the graph, the hydrogen concentration of the samples was constant regardless of the thickness of the samples. The thickness of the thickest chips was the same as that of the fatigue test specimen. Therefore, it is reasonable to consider that the hydrogen in the fatigue test specimen was uniformly distributed throughout the thickness.

The hydrogen concentration was approximately 22.1 mass ppm for the UFG16-10 and 22.4 mass ppm for the CG16-10. According to the TDS result, there was almost no effect of the grain size on the hydrogen content, although there is the result that grain refinement increased the amount of absorbed hydrogen [22]. Since the volume fraction of the grain boundary rapidly increases with a decrease in the grain size in the region where the grains are finer than $1 \mu \mathrm{m}$ [23], it can be considered that the volume fraction of the grain boundary in the UFG16-10 was not very different from that in the CG16-10. This is the reason for that the hydrogen contents were almost the same for the UFG1610 and the CG16-10.

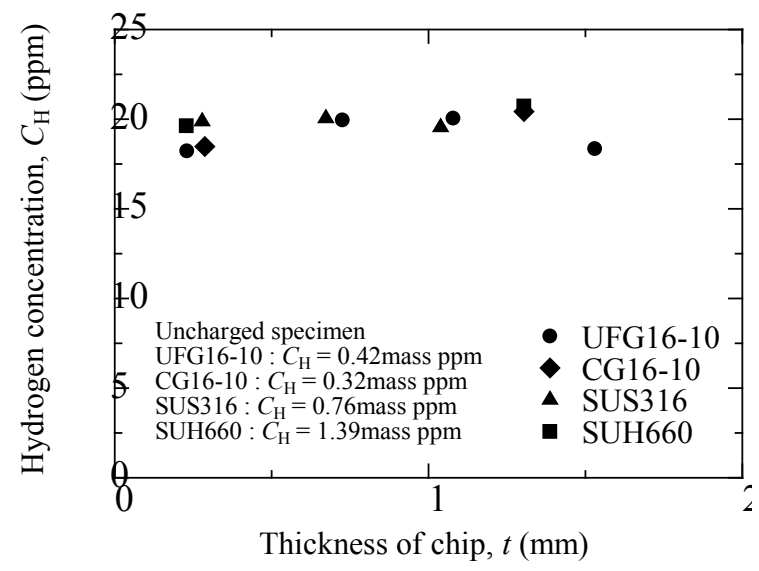

Fig. 3. Hydrogen concentration of the hydrogen charged samples having different thicknesses

\section{Effect of hydrogen on fatigue strength}

The $S$ - $N$ curves were obtained by the specimen shown in Fig. 4. The thickness of the specimen was $1.5 \mathrm{~mm}$. Small specimens are often used in the study of ultra-fine grain materials $[2,10]$, however the size of the ultra-fine grain steel used in this study was bulk size. The specimen had blunt notches, which stress concentration factor was 1.47 , to prevent buckling of the specimen during the compression loading and to avoid heating of the specimen during the fatigue loading. It was confirmed that there was no significant increase in the temperature of the specimen during the fatigue test. The surface of the notch root was finished by buffing.

The fatigue tests were carried out under a tensioncompression loading with a stress ratio, $R$, of -1 at a loading frequency, $f$, of $15 \mathrm{~Hz}$ at room temperature in laboratory air.
Figure 5 shows the $S-N$ curves of the UFG16-10 and the reference materials. The stress amplitude in the graph is the nominal value at the notch root. The fatigue limit of the UFG16-10 was 2.8 times higher than that of the CG16-10. The grain refinement was very effective in improving not only the static strength [21] but also the fatigue strength of the $16 \mathrm{Cr}-10 \mathrm{Ni}$ steel. Furthermore, the UFG16-10 had a higher fatigue strength than the SUH660 despite the fact that the ultimate tensile strength of the SUH660 is slightly higher than that of the UFG1610.

The fatigue strength of the CG16-10 was very similar to that of the SUS316. This is reasonable when considering the similar tensile strengths of these materials and the empirical relationship between the ultimate tensile strength and fatigue limit.

The effect of the hydrogen on the fatigue strength is also shown in Fig. 5. The reduction in the fatigue limit of the UFG16-10 by the hydrogen charge was not significant. For austenitic stainless steels, workhardening is frequently used to improve mechanical properties. However, in some cases, the work-hardened austenitic stainless steels severely suffer from hydrogenassisted fatigue failure [24, 25]. The result of this study clearly demonstrated the significant potential of the UFG steel to be a high-strength austenitic steel for hydrogen service systems use.

On the other hand, the fatigue life of the UFG16-10 in the short life region was significantly reduced by the hydrogen. In the short life region, crack growth is dominant rather than crack initiation, the crack growth behavior of the materials were investigated.

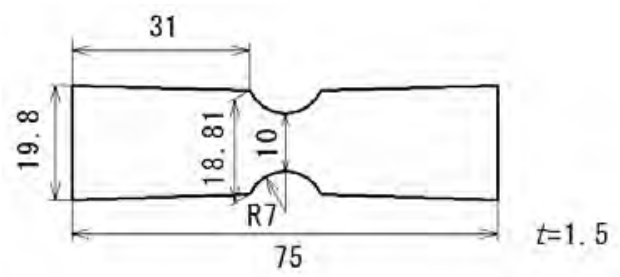

Fig. 4. Fatigue test specimen for $S-N$ test

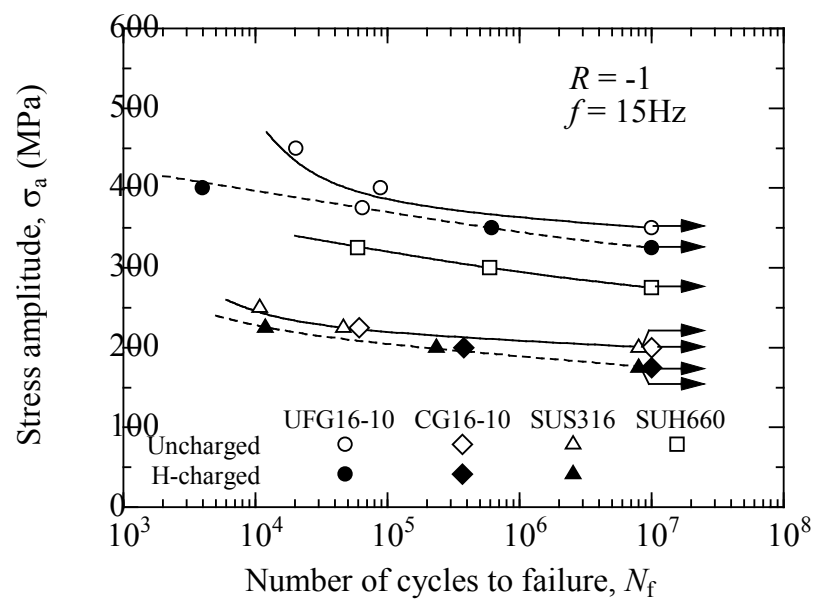

Fig. 5. Fatigue strength of the UFG16-10 and the effect of hydrogen 


\section{Effect of hydrogen on fatigue crack growth}

The crack growth test was carried out using a CT specimen shown in Fig. 6. According to the material processing method shown in Fig. 1, there is no limitation of the thickness of the UFG16-10. However, for our experiment, the maximum thickness of the UFG16-10 specimen was $1.5 \mathrm{~mm}$ because of the capacity of the rolling mill we have.

Therefore, the thickness of the CT specimen was also 1.5 $\mathrm{mm}$. Even so, plain strain condition was achieved in the UFG16-10 and the SUH660 within the stress intensity factor range that the experiment was done because the yield strengths of both materials were sufficiently high. For the SUS316, the plain stress condition was not achieved. Since crack growth resistance in the plain stress condition is higher than that in the plain strain condition [26], it should be noted that the crack growth resistance of the SUS316 in this study was apparently high.

The crack growth test was performed at $f=5 \mathrm{~Hz}$ and $0.5 \mathrm{~Hz}$ with $R=0.1$ at room temperature in laboratory air. The slower loading frequency was adopted by considering the experimental fact that the effect of hydrogen on the fatigue crack growth behavior was enhanced with a decrease of the loading frequency [27]. The crack length was measured by an unloading elastic compliance method using a back face strain gauge.

Figure 7 shows the results of the crack growth test. For the uncharged materials, the crack growth rate of the UFG16-10 was remarkably low compared to that of the SUS316, and it was equivalent to that of the SUH660. It is presumed that this higher crack growth resistance contributed to the significantly improved fatigue strength of the UFG16-10.

Regarding crack growth resistance, there is a report that grain refinement has a negative impact on the crack growth resistance [15]. The mechanism that achieved the excellent crack growth resistance in the UFG16-10 was discussed in the separated paper [28]. In brief, the crack tip opening displacement (CTOD) was reduced by the small grains as shown in Fig. 8. According to the established crack growth theory, crack growth rate is proportional to the CTOD [29]. The reason why the CTOD was reduced by the small grain was the reduction of stress concentration at the grain boundary ahead of the crack tip due to piling up of dislocations and consequent reduction in the plastic deformation at the crack tip. The CTOD is proportional to the square of the stress intensity factor, and the plastic zone size at the crack tip is also proportional to the square of the stress intensity factor [30]. Then, the CTOD is proportional to the plastic zone size.

For the hydrogen charged materials, the crack growth rate of the UFG16-10 was accelerated by hydrogen. It was consistent with the significant reduction in the fatigue life of the UFG16-10 in the short fatigue life regime due to hydrogen shown in Fig. 5. The acceleration became more significant with the decrease in the loading frequency.

The accelerated fatigue crack growth was also found in the SUS316. On the other hand, the SUH660 did not suffer from hydrogen-assisted crack growth. The acceleration of the crack growth by hydrogen was grater in the order of the UFG16-10, SUS316 and SUH660. According to the past study, stability of austenite was closely related to the hydrogen-assisted fatigue crack growth [16]. Nickel equivalent that is an index of austenite stability that was calculated by Oshima's equation [31] was 18.3 for the UFG16-10, 20.2 for the SUS316 and 32.0 for the SUH660. The fact that the order of the nickel equivalent values was consistent with that of the degree of the acceleration of the crack growth implied the accelerated crack growth of the UFG16-10 was caused by the transformation of microstructure to strain-induced martensite at the crack tip during the crack growth.

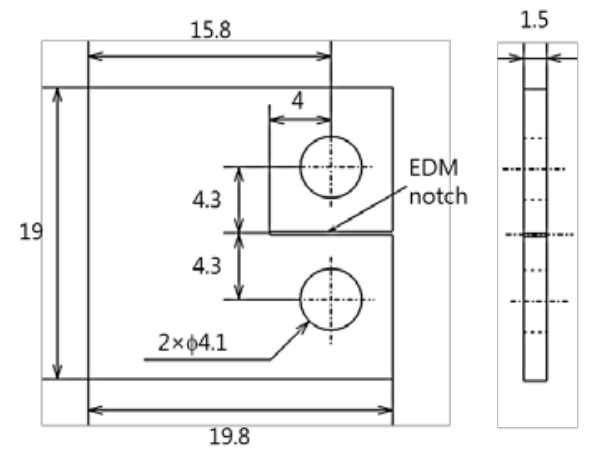

Fig. 6. CT specimen for fatigue crack growth test

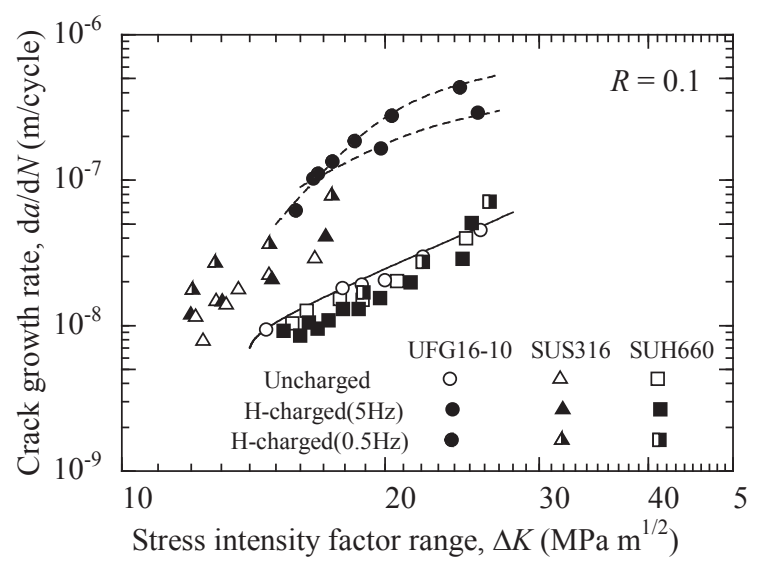

Fig. 7. Results of crack growth test and the effects of hydrogen and loading frequency 

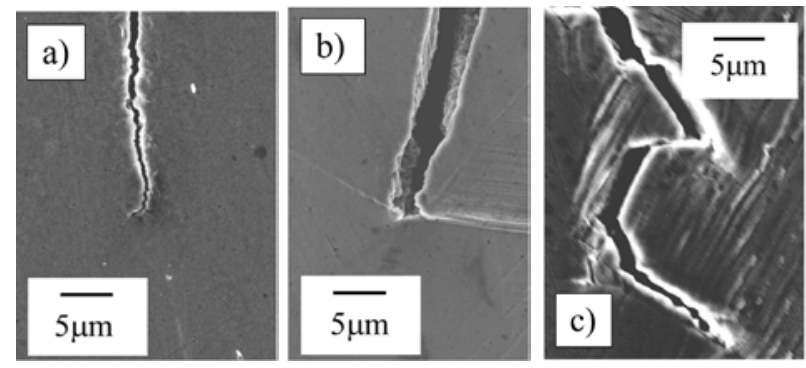

Fig. 8. Crack tip opening displacement at similar $\Delta K$. a) UFG16-10. $\Delta K=22.1 \mathrm{MPa} \mathrm{m}^{1 / 2}$. b) SUS316. $\Delta K=19.3$ $\mathrm{MPa} \mathrm{m}^{1 / 2}$. c) SUH660. $\Delta K=23.1 \mathrm{MPa} \mathrm{m}^{1 / 2}$.

Figure 9 shows the fracture surface of the UFG16-10. The fracture surface of the uncharged material showed a ductile feature and transgranular crack path. In the case that the grain refinement reduced the crack growth resistance, the fracture surface showed brittle feature [18]. Therefore, the good fatigue crack growth behavior of the uncharged UFG16-10 could be achieved by maintaining ductile crack growth.

The fracture surface of the hydrogen-charged material exhibited a granular pattern. The morphology of the fracture surface was clearly different. As shown in Fig. 9 c), the unit size of the granular pattern was almost equivalent to the grain size. It revealed the crack growth mechanism was changed to an intergranular cracking. Cracking at twin boundary might also be mixed. It was obvious that the change in the crack growth mechanism due to hydrogen caused the accelerated crack growth in the hydrogen charged UFG16-10.
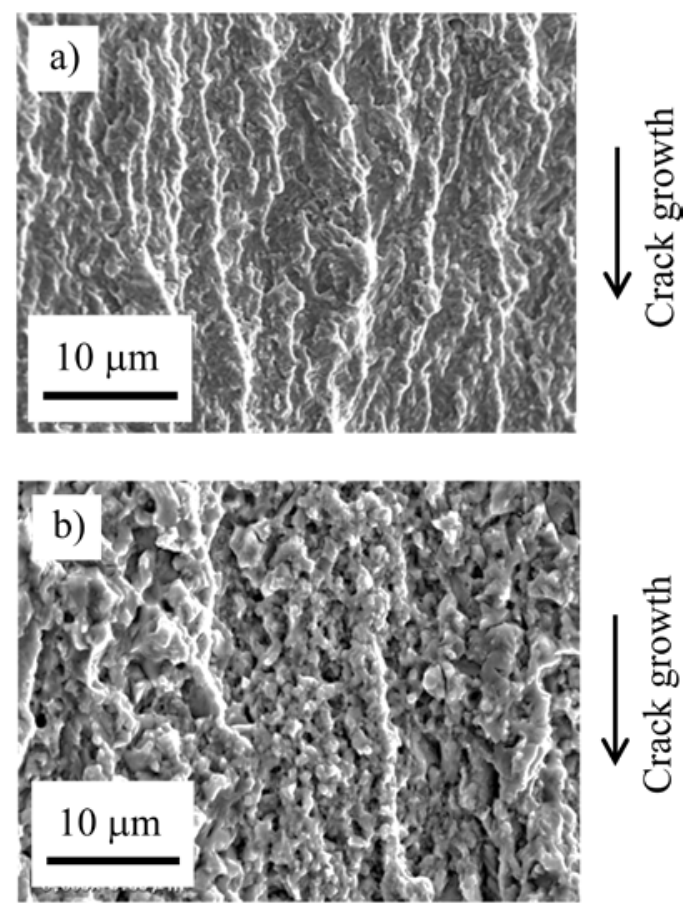
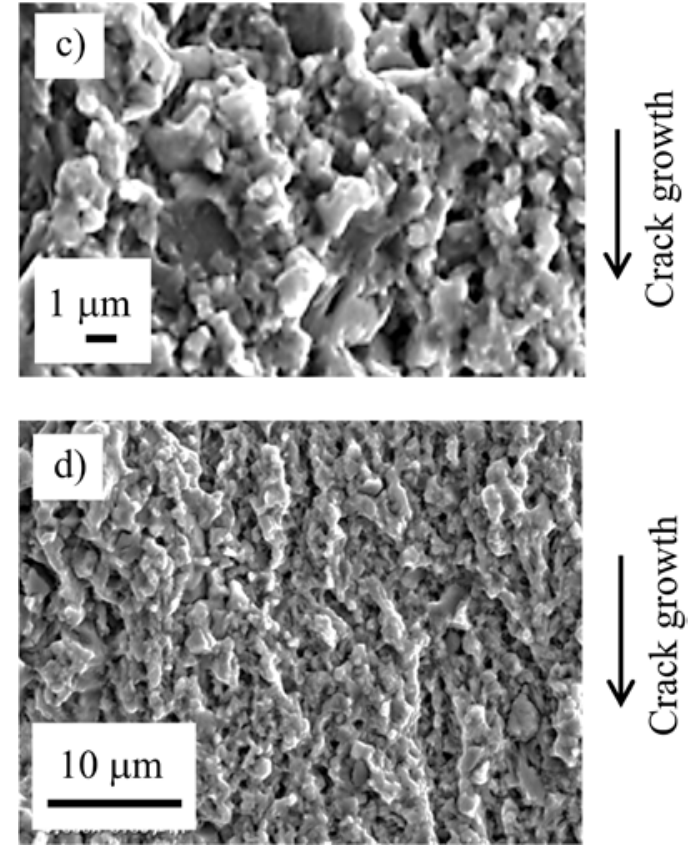

Fig. 9. Fracture surfaces of the UFG16-10 observed at $\Delta K=20$ $\mathrm{MPa} \mathrm{m}^{1 / 2}$. a) Uncharged. b) Hydrogen charged, $f=5$ Hz. c) Enlarged view of b). d) Hydrogen charged, $f=$ $0.5 \mathrm{~Hz}$.

\section{Effect of hydrogen on crack initiation}

The fatigue failure process can be divided into two stages, crack initiation and crack propagation. Thus, the effect of hydrogen on the crack initiation behavior of the UFG16-10 was also investigated.

The fatigue test for the observation of crack initiation was carried out under a tension and compression loading at $f=5 \mathrm{~Hz}$ with $R=-1$ at room temperature in laboratory air. Figure 10 shows the specimen. The specimen has blunt notches to facilitate crack observation. The notch root was observed by a surface replication technique. The notch root was finished by buffing. Since the effect of hydrogen on the fatigue life of the UFG16-10 was significant in the short life regime as shown in Fig. 5, the crack initiation behavior was observed in the short life regime.

The crack initiation behavior of the UFG16-10 is shown in Fig. 11. The fatigue crack originated from a non-metallic inclusion. The reproducibility was confirmed by multiple specimens. The size of the inclusion was approximately $2 \mu \mathrm{m}$. It was very small compared with the sizes of the inclusions that lead crack initiation in other commercial high-strength steels [32]. In addition, this type of crack initiation is found in the high-strength steels having the UTS more than $1.2 \mathrm{GPa}$ or the hardness more than HV400 [33]. Therefore, it might be considered special mechanisms due to small grains to the crack initiation of the UFG16-10.

Figure 12 shows the crack initiation behavior of the hydrogen-charged UFG16-10. The fatigue life of this hydrogen-charged specimen was significantly shorter than that of the uncharged specimen shown in Fig. 11. 
Similar to the uncgarged material, the crack originated from an nonetallic inclusion.

Figure 13 shows the crack length as a function of the number of cycles. Whereas the fatigue life was significantly reduced by hydrogen, the crack initiation lifves of the hydrogen-charged and uncharged materials were not much different. In the subsequent crack propagation of the crack length reached approximartely $10 \mu \mathrm{m}$, the small crack of the hydrogen-charged material grew fatser than that of the uncharged one. The results of the observations of the crack initiation and small crack propagation showed that hydrogen had no significant effect on the crack initiatin of the UFG16-10 and accelerated the small crack propagation. As shown in Fig. 7, the propagation of the large crack was also accelelated by hydrogen. Therefore, the reduced fatigue life of the hydrogen-charged UFG16-10 was due to acceleration of the crack growth by hydrogen.

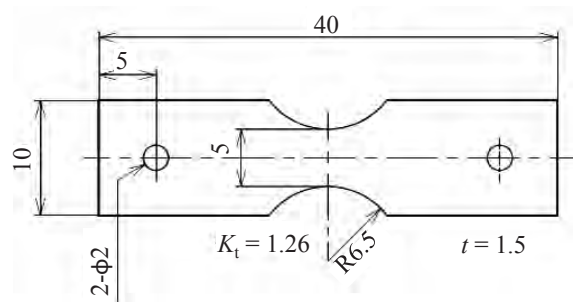

Fig. 10. Fatigue test specimen for identification of crack origin

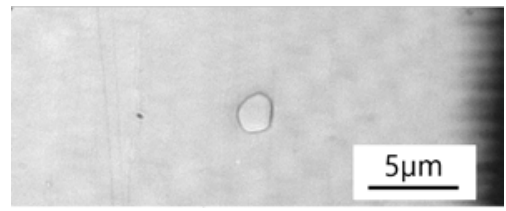

a) $N=0, N / N_{\mathrm{f}}=0$

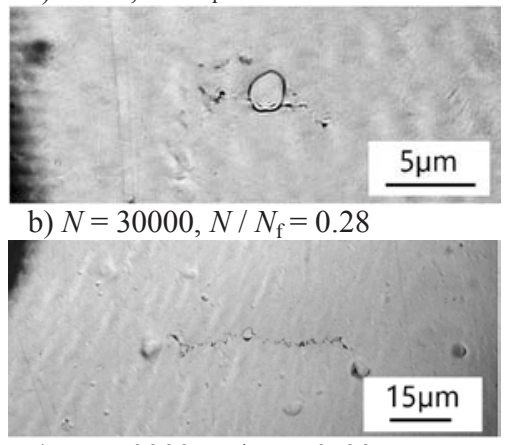

c) $N=70000, N / N_{\mathrm{f}}=0.66$

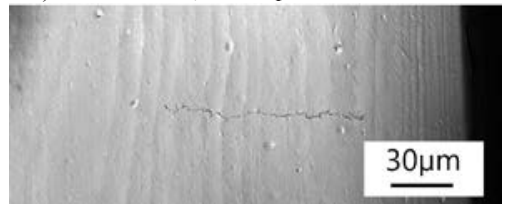

d) $N=80000, N / N_{\mathrm{f}}=0.75$

Fig. 11. Crack initiation of the uncharged UFG16-10. The stress amplitude at the notch root was $660 \mathrm{MPa}$. The fatigue life was 106500 cycles.

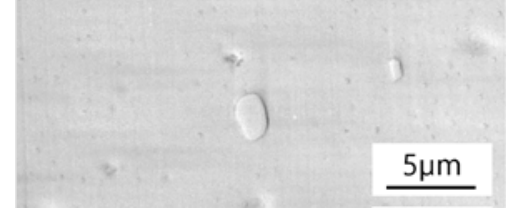

a) $N=0, N / N_{\mathrm{f}}=0$

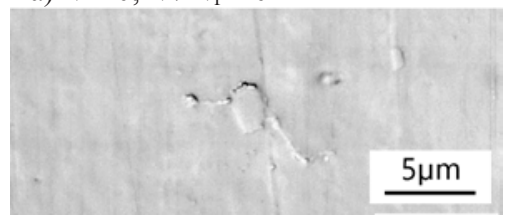

b) $N=20000, N / N_{\mathrm{f}}=0.24$

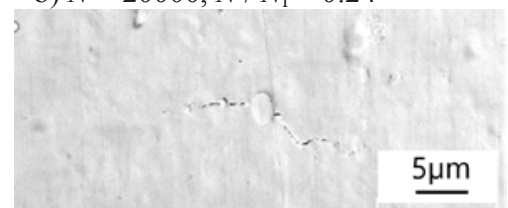

c) $N=40000, N / N_{\mathrm{f}}=0.47$

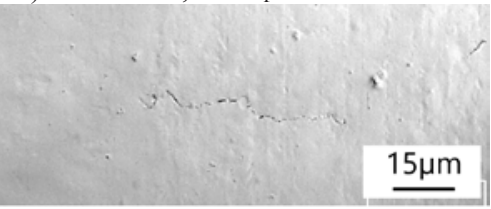

d) $N=60000, N / N_{\mathrm{f}}=0.72$

Fig. 12. Crack initiation of the hydrogen-charged UFG16-10. The nominal stress amplitude at the notch root was $523 \mathrm{MPa}$. The fatigue life was 83500 cycles.

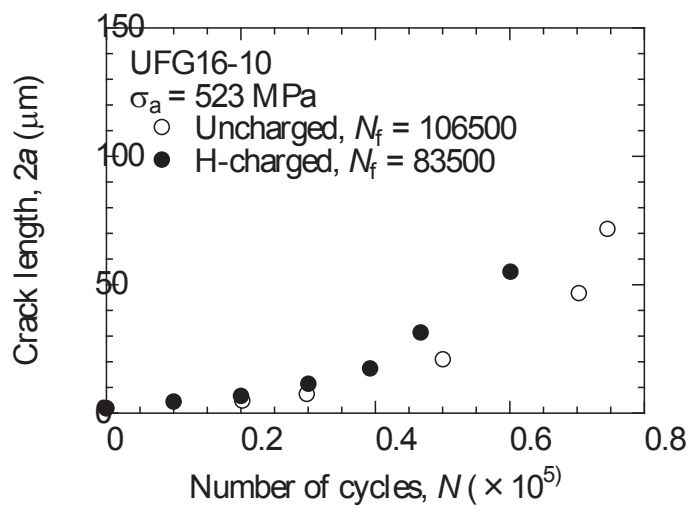

Fig. 13. Effect of hydrogen on the crack initiation and the small crack propagation of the UFG16-10.

\section{Conclusion}

The effect of hydrogen on the fatigue properties of the ultra-fine grain austenitic stainless steel (UFG16-10) was studied.

(1) The fatigue limit of the uncharged UFG16-10 was 2.8 times higher than that of the CG16-10. The fatigue limit of the UFG16-10 was reduced by hydrogen, however, the reduction was no so significant.

(2) The fatigue life of the UFG16-10 was significantly reduced by hydrogen.

(3) The crack growth resistance of the uncharged UFG16-10 was significantly higher than that of SUS316 and equivalent to that of the SUH660. 
However, the severe hydrogen-assisted crack growth occurred in the UFG16-10.

(4) The crack origin was a non-metallic inclusion for both hydrogen-charged and uncharged specimens. There was no significant change in the crack initiation life due to hydrogen.

(5) The cause of the reduced fatigue life of the hydrogencharged specimen was the accelerated crack growth by hydrogen.

The ultra-fine grain austenitic stainless steel used in this study was provided by Professor Setuo Takaki at the Research Center for Steel, Kyushu University. All members in the Professor Takaki's laboratory provided us excellent support for this research. This study was also supported by the World Premier International Research Center Initiative (WPI), MEXT, Japan. The International Institute for Carbon-Neutral Energy Research (WPI-I2CNER) is supported by the World Premier International Research Center Initiative (WPI), MEXT, Japan.

\section{References}

1. M. Goto, N. Teshima, S. Z. Han, K. Euh, T. Yakushiji T, S. S. Kim, J. Lee, Engng Fract. Mech. 110, 218 (2013)

2. J. Horky, G. Khatibi, B. Weiss, M. J. Zehetbauer, J Alloys and Compounds 509 (1), 323 (2011)

3. H. Kitahara, S. Matsushita, M. Tsushida, S. Ando, Materials Transactions 54 (4), 528 (2013)

4. N. Nagashima, Y. Furuya, Y. Kimura, T. Inoue, Trans. JSME A78-790, 923 (2012)

5. S. Brochet, A. B. Quintin, J. B. Vogt, J. C. Glez, J. D. Mithieux, Proc. ECF-16, Alexandroupolis, Greece, 2006.

6. Nippon steel and Sumitomo metal, Press release 2013, http://www.nssmc.com/news/20131203 100.html, Refered on March 23th, 2018

7. F. Akbaripanah, F. Fereshteh-Saniee, R. Mahmudi, H. K. Kim, Mater. Sci. Engng A565, 308 (2013)

8. S. Z. Han, M. Goto, C. Lim, C. J. Kim, S. Kim, Alloys and Compounds 434-435, 304 (2007)

9. J. C. Pang, M. X. Yang, G. Yang, S. D. Wua, S. X. Li, Z. F. Zhang, Mater. Sci. Engng A553, 157 (2012)

10. M. Okayasu, K. Sato, M. Mizuno, D. Y. Hwang, D. H. Shin, Int J Fatigue 30, 1358 (2008)

11. C. Ruffing, E. Kerscher, Adv. Mater. Res. 891-892, 428 (2014)

12. H. Ueno, K. Kakihata, Y. Kaneko, S. Hashimoto, A. Vinogradov, Acta Materialia 59, 7060 (2011)

13. K. Suzuki, T. Shimizu, Y. Todaka, K. Koujima, T. Yakushiji, M. Nakajima, J Japan Soc. Abrasive Technology 56-2, 112 (2012)

14. J. H. Kim, S. K. Hwang, Y. T. Im, I. H. Son, C. M. Bae, Mater. Sci. Engng A552, 316 (2012)
15. H. K. Kim, M. I. Choi, C. S. Chung, D. H. Shin, Mater. Sci. Engng A340, 243 (2003)

16. H. Itoga, T. Matsuo, A. Orita, H. Matsunaga, S. Matsuoka, Trans JSME A79-808, 1726 (2013)

17. H. Matsunaga, M. Yoshikawa, R. Kondo, J. Yamabe, S. Matsuoka, Hydrogen Energy 40, 5739 (2015)

18. T. Miyomoto, T. Matsuo, N. Kobayashi, Y. Mukaie, S. Matsuoka, Trans. JSME A78-788, 531 (2012)

19. K. Tomimura, S. Takaki, Y. Tokunaga, Tetsu-toHagane 74-8, 1649 (1988)

20. S. Takaki, S. Tanimoto, K. Tomimura, Y. Tokunaga, Tetsu-to-Hagane 74-6, 1052 (1988)

21. A. Macadre, K. Tsuboi, N. Nakada, T. Tsuchiyama, S. Takaki, Procedia Mater. Sci. 3, 350 (2014)

22. M. Noda, S. Ishida, K. Funami, J Japan Inst. Light Metals 59-1, 13 (2009)

23. N. Tsuji, Tetsu-to-Hagane 88-7, 359 (2002)

24. E. Takeuchi, M. Hayakawa, N. Nagashima, Y. Furuya, S. Matsuoka, Trans. JSME A73-736, 1335 (2007)

25. Y. Kondo, M. Kubota, K. Ohguma, K. Shimada, Trans. JSME A73-736, 1351 (2007)

26. K. Tokaji, Z. Ando, K. Nagae, Trans. JSME 52-475, 655 (1986)

27. M. Yoshikawa, T. Matsuo, N. Tsutsumi, H. Matsunaga, S. Matsuoka, Trans. JSME 80-817, SMM0254 (2014)

28. M. Kubota, M. Arnaud, K. Mori and R. Mori, ISIJ internatioal, under review

29. R. Pippan, C. Zelger, E. Gach, C. Bichler and H. Weinhandl, FFEMS 34, 1 (2010)

30. N. E. Frost, K. J. Narsh, L. P. Pook, Metal fatigue, Dover Publications, Inc., 1999.

31. T. Oshima, Y. Habara, K. Kuroda, Tetsu-to-Hagane 93-8, 544 (2007)

32. Y. Murakami, Metal fatigue : Effect of small defect and nonmetallic inclusions, Elsevier, 2002

33. M. Saito, K. Ito, Trans. JSSE, 30, 11 (1985) 